\title{
Alterações de comportamento na encefalite herpética: um caso polimórfico e de difícil manejo
}

\author{
Behavior changes in herpes encephalitis: a \\ polymorphic case with difficult management \\ Gustavo Carvalho de Oliveira', Moema de Carvalho Madeira', Margareth Diniz Celmer'
}

\section{RESUMO}

A encefalite herpética é uma doença de alta mortalidade que deve ser diagnosticada e tratada rapidamente. Cefaleia, febre e alteração de comportamento compõem a tríade clássica. Há escassos estudos sobre o tema e nenhum a respeito do manejo das manifestações psiquiátricas. O relato de caso se refere a paciente de 35 anos, que manifestou a tríade clássica, sendo diagnosticado e tratado corretamente. Após um mês, apresentou desorganização do comportamento e agitação, sendo reinternado. Foi descartada recidiva e, por sua grave agitação, ele foi transferido à Psiquiatria. Permaneceu internado por 116 dias; nesse período, teve seguidos episódios de agitação e heteroagressividade, sendo restrito ao leito na maior parte do tempo. Apresentou crises epilépticas do tipo parcial complexa, somente realizando eletroencefalograma sob a terapêutica de três anticonvulsivantes, quando pôde colaborar para a realização do exame, com resultado normal. Houve intercorrências infecciosas tratadas, e conseguiu-se estabilização parcial com o uso de seis psicotrópicos em doses elevadas. Na alta, apresentava comportamento desorganizado, déficit de memória, raciocínio fragmentado, construção de conceitos de forma errática, com interpretações delirantes, impulsividade latente, mas sem agressividade. Desafios do caso: internação prolongada pela refratariedade terapêutica, riscos, desgaste físico e emocional para paciente, família e equipe de saúde. O resultado final demonstra a possibilidade de melhora parcial em um caso polimórfico de encefalite herpética.

\section{ABSTRACT}

Herpes encephalitis is a high-mortality disease that must be quickly diagnosed and treated. Headache, fever and behavioral changes are the classic triad. There are few studies on the topic and none focus specifically on the management of psychiatric manifestations. The case report refers to 35 -year-old patient who had those symptoms and was diagnosed and treated properly. One month later he showed disorganized behavior and agitation, and was readmitted. Herpes infection relapse was discarded, and he was transferred to the psychiatric ward, where he remained hospitalized for 116 days. During that time he became more agitated and even aggressive, and at one point began to undergo complex

1 Hospital de Base do Distrito Federal, Unidade de Psiquiatria.

Recebido em$$
\text { 5/8/2015 }
$$

Aprovado em

$5 / 11 / 2015$

DOI: 10.1590/0047-2085000000094
Endereço para correspondência: Gustavo Carvalho de Oliveira Unidade de Psiquiatria, Hospital de Base do Distrito Federal Quadra 101, Bloco B - Área Especial - 71330-150 - Braślia, DF, Brasil E-mail: psiquiatragustavo@gmail.com 


\section{Keywords}

Encephalitis, herpes

simplex, psychotic

disorders, therapeutics, epilepsy. partial seizures. Electroencephalogram results were normal. Partial stabilization required six psychotropic drugs at high doses. At discharge he was no longer aggressive and his behavior was less disorganized, but he had poor memory, fragmented thinking, delusional interpretations, and latent impulsiveness. Case challenges: long-term hospitalization, risks, physical and emotional distress for patients, family, and health professionals. The final results show that an important, albeit partial, improvement may be achieved in a polymorphic case of herpetic encephalitis.

\section{INTRODUÇÃO}

A encefalite herpética é uma doença de alta mortalidade $(70 \%)^{1-3}$ que apresenta uma tríade clássica de sintomas: febre, cefaleia e alterações de comportamento 1,3,4.

Se não diagnosticada e tratada rapidamente, o prognóstico é bastante sombrio, podendo chegar a quase $100 \%$ de mortalidade ${ }^{1,4}$. Mesmo os sobreviventes que foram tratados apresentam importantes sequelas, em uma proporção elevada, conforme se nota em alguns estudos ${ }^{5}$.

O diagnóstico de certeza deve envolver a reação de cadeia de polimerase para herpes vírus ${ }^{6,7}$, que é utilizada como padrão em trabalhos sobre a temática ${ }^{7,8}$.

Pacientes com doenças orgânicas que cursam com manifestações psiquiátricas são um constante desafio. A investigação diagnóstica extensa é extremamente importante e pode revelar novas patologias envolvidas, como mostram muitos trabalhos ${ }^{5-7,9}$.

No caso em tela, o paciente apresentou complicações e alterações de comportamento secundárias à encefalite herpética, além de crises epilépticas.

\section{RELATO DO CASO}

MNS, 35 anos, sexo masculino, casado, ensino fundamental completo, pardo, compleição avantajada, representante comercial, católico, natural e procedente de Brasília, Distrito Federal (DF). Previamente hígido, sem quaisquer comorbidades, bem como ausência de antecedente familiar de doença mental.

Motivo da internação: agitação psicomotora e desorganização do comportamento há uma semana.

MNS deu entrada em hospital da rede suplementar, por ter apresentado, de forma aguda: cefaleia, febre alta e agitação, seguidas de crise convulsiva. Realizou exames laboratoriais, que revelaram hemograma com intensa linfocitose, além de tomografia de crânio normal. Por causa da gravidade clínica, foi internado em unidade de terapia intensiva (UTI), tendo realizado ressonância nuclear magnética (RNM) de crânio com contraste, que mostrou lesões compatíveis com infecção por Herpes simplex vírus 1. Laudo: "Hipersinal em lobo temporal e córtex da ínsula à esquerda, compatível com indicação clínica de encefalite". Foi tratado com aciclo- vir endovenoso por 14 dias, com melhora de seu quadro, tendo recebido alta a seguir.

Após um mês, apresentou agitação psicomotora e desorganização do comportamento, tendo sido levado a hospital terciário da rede pública do DF. Foi avaliado pela equipe da Neurologia, descartando-se recidiva, após investigação laboratorial e radiológica. Em virtude da extrema agitação e desorganização do comportamento, foi encaminhado à equipe de Psiquiatria.

A partir da internação em enfermaria de Psiquiatria, o paciente se manteve extremamente agitado, desorganizado e com comportamentos imprevisíveis, com ameaças e agressões contra membros da equipe de saúde e outros pacientes. A prescrição inicial era de haloperidol, ácido valproico e clorpromazina.

No sétimo dia de internação hospitalar (DIH), foi solicitada reavaliação da Neurologia, durante a qual ocorreu crise epiléptica do tipo parcial complexa. Foram sugeridas retirada de antipsicóticos e realização de eletroencefalograma. Assim, foi optado por aumento do ácido val proico e retirada dos antipsicóticos. Paciente teve evolução com aumento da agitação e da impulsividade, com seguidos episódios de heteroagressividade. Necessitou ficar contido no leito durante a maior parte da internação.

No $10^{\circ} \mathrm{DIH}$, foi realizada RNM de crânio, que não revelou alterações agudas. Paciente manteve-se com comportamento desorganizado e imprevisível, além de desagregação do pensamento. Até o $30^{\circ} \mathrm{DIH}$, foram feitas mudanças na prescrição, com aumento de ácido valproico até $2 \mathrm{~g} / \mathrm{d}$, fenobarbital até $300 \mathrm{mg} / \mathrm{d}$ e, posteriormente, associação de clorpromazina, com finalidade sedativa. O paciente era lábil, por vezes estava calmo e com interação fugaz, mas na maior parte do tempo tinha comportamento imprevisível, discurso incoerente e agressividade súbita.

No $32^{\circ} \mathrm{DIH}$, conseguiu-se, enfim, sedação com segurança para a realização de nova punção liquórica, que mostrou rotina de líquidos normal e sorologias lgG positiva e lgM negativa para Herpes simplex vírus 1, confirmando-se infecção prévia pelo vírus, já curada. Logo, o quadro decorria de sequelas lesionais, com provável foco epileptogênico em lobo temporal. As sorologias para HIV (vírus da imunodeficiência humana), síflis, toxoplasmose, hepatites B e C, citomegalovírus (CMV), Criptococcus e tuberculose tiveram resultado não reagente. 
Após novo parecer à equipe da Neurologia, recomendou-se substituição gradual dos anticonvulsivantes por carbamazepina, considerando a epilepsia do lobo temporal. Tal proposta foi seguida do $33^{\circ}$ ao $45^{\circ} \mathrm{DIH}$, mas ocorreu piora progressiva do paciente, que se tornou mais agitado, impulsivo e desorganizado. A situação era agravada em razão de sua compleição avantajada e extrema força física, o que ocasionava danos materiais à unidade de internação, além de agressões repetidas e inesperadas contra a equipe e demais pacientes.

Entre o $45^{\circ}$ e o $58^{\circ} \mathrm{DIH}$, foi optado por suspensão gradual da carbamazepina e restabelecimento das doses anteriores dos anticonvulsivantes. O paciente passou a melhorar gradualmente, embora ainda muito oscilante e impulsivo. Foi feita tentativa de uso de clobazam e diazepam, sem melhora. A hipótese para explicar a piora com a carmabazepina foi a interação com as demais medicações ou efeito paradoxal.

Entre o $58^{\circ} \mathrm{DIH}$ e o $88^{\circ} \mathrm{DIH}$, em virtude da observação de que o ácido valproico provocara sua melhora, optou-se por aumentar a dose para até $3 \mathrm{~g}$ por dia, acompanhado de dosagens séricas, sempre na janela terapêutica. Foi notada progressiva melhora, mas, como ainda estava muito impulsivo, foi associada lamotrigina até a dose de 100 mg/dia, pelo potencial de sinergismo e de estabilizador do humor. $\mathrm{O}$ clonazepam foi introduzido, com boa resposta ansiolítica e melhora de seu sono, que até então seguia sempre irregular.

Apenas no $89^{\circ} \mathrm{DIH}$, conseguiu-se deixá-lo livre de contenção mecânica, e foi realizada entrevista em consultório, pela primeira vez. Nesta, ele conseguiu dar informações sobre sua história de vida, não se recordou de como chegou à internação e, após ouvir a explicação do médico sobre os detalhes de sua doença, conclui que "ficou louco" e que suas filhas iriam morrer por causa disso. Havia diversas interpretações delirantes, delírios místicos e de relação. Por isso, optou-se por reintrodução de haloperidol 5 mg, com incremento gradual de sua dose.

Do $90^{\circ} \mathrm{DIH}$ ao $93^{\circ} \mathrm{DIH}$, o paciente mostrou-se muito desorganizado, quebrou objetos e, em seguida, pediu perdão e solicitou que fosse amarrado. Por vezes, voltava a ficar calmo. O haloperidol foi aumentado para 7,5 mg/d e, quando ele parecia melhor, tornou-se subitamente agressivo, invadiu a sala dos médicos, quebrou a tampa da mesa de vidro e rasgou diversos papéis e fotos no local. Manteve-se a estratégia de uso progressivo do antipsicótico, em razão de seu exame psíquico em consultório, associado aos anticonvulsivantes, com otimização das doses.

No $110^{\circ} \mathrm{DIH}$, O paciente resolvia palavras cruzadas, preenchia formulários, lia revistas e escrevia algumas frases. No $113^{\circ} \mathrm{DIH}$, apresentou, enfim, boa interação com os demais pacientes e confidenciou ao médico que gostava de uns, mas que tinha raiva de outros, mas sabia que não poderia agredi-los. Solicitava muito a alta, falava da saudade de sua família, mas começou a tolerar o fato de ter de aguardar até "um milhão de anos", conforme dizia. Devido à melhora da agitação, finalmente se realizou o eletroencefalograma, cujo resultado foi normal, porém ele já estava polimedicado.

No $115^{\circ} \mathrm{DIH}$ não apresentou delírios espontaneamente e discurso tinha um padrão mais organizado, porém pobre e concreto. O comportamento mostrou-se adequado, embora pueril.

No $116^{\circ} \mathrm{DIH}$, houve alta médica. No exame psíquico, apresentou: comportamento parcialmente desorganizado, déficit de memória, raciocínio com algumas incoerências, presença de interpretações delirantes, impulsividade latente, mas com capacidade de autocontrole e sem agressividade. Prescrição: haloperidol $15 \mathrm{mg} /$ dia, prometazina $50 \mathrm{mg} /$ dia, ácido val proico 3 g/d, lamotrigina 100 mg/dia, fenobarbital 200 mg/dia, clorpromazina 300 mg/dia e clonazepam 4 mg/dia.

\section{DISCUSSÃO}

Trata-se de um caso singular e de difícil manejo, dada a raridade da encefalite herpética e sua elevada mortalidade $(70 \%)^{1-3}$. Há poucos estudos sobre o tema, especificamente nenhum a respeito do manejo dos sintomas psiquiátricos resultantes.

Alterações cognitivas e comportamentais relacionadas à encefalite herpética são conhecidas e descritas na literatura como amnésias, afasias, mudanças de personalidade, alucinações e desinibição ${ }^{5-9}$.

O paciente apresentou gravíssimas alterações de comportamento, que poderiam ser resultantes não apenas da lesão sequelar da infecção, mas também da gravidade dessas lesões, capazes de originar um foco epiléptico em seu lobo temporal. Seu exame psíquico mostrou-se polimórfico, com oscilação e diversificação das manifestações psicopatológicas, que caracterizam as alterações psiquiátricas resultantes de outras condições médicas.

Quanto ao manejo medicamentoso, houve necessidade de polimedicação, associações terapêuticas e uso de doses muito elevadas. A carbamazepina, em tese ótima opção para epilepsia do lobo temporal, foi ineficaz para esse caso, o que pode ser explicado pela interação adversa ou efeito paradoxal. Observou-se boa resposta com a associação de ácido valproico e lamotrigina, além da necessidade do uso de antipsicótico.

O caso gerou dificuldades para a equipe de saúde, paciente e familiares, com internação prolongada repleta de riscos, ocorrência de agressões, desgaste físico e emocional constantes, pela imprevisibilidade das manifestações.

\section{CONCLUSÃO}

O resultado satisfatório ao final demonstra a possibilidade de melhora parcial em um caso polimórfico de encefalite her- 
pética. O paciente mantém acompanhamento ambulatorial, com progressiva melhora cognitiva e comportamental.

\section{CONTRIBUIÇÕES INDIVIDUAIS}

Gustavo Carvalho de Oliveira - Levantamento de revisão bibliográfica sobre o tema, redação do texto do artigo, além de tratamento ativo do paciente durante todo o período da internação. Além da redação inicial, fez também a revisão final, após a revisão dos demais autores.

Moema de Carvalho Madeira - Levantamento adicional de revisão bibliográfica, revisão e interpretação dos resultados, com discussão aprofundada do caso e do texto escrito, além do tratamento ativo do paciente durante todo o período da internação.

Margareth Diniz Celmer - Levantamento adicional de revisão bibliográfica, revisão e interpretação dos resultados, com discussão aprofundada do caso e do texto escrito, além do tratamento ativo do paciente durante todo o período da internação.

\section{CONFLITOS DE INTERESSE}

Não há conflitos de interesse e nenhum auxílio financeiro de qualquer natureza.

\section{AGRADECIMENTOS}

Os autores agradecem à equipe de saúde do Hospital de Base do Distrito Federal, ao paciente e a seus familiares.

\section{REFERÊNCIAS}

1. Kennedy PGE, Chaudhuri A. Herpes simplex encephalitis: Herpes simplex virus encephalitis still has an unacceptably high mortality. J Neurol Neurosurg Psychiatry. 2002;73:237-8.

2. Silva GMM. Encefalites virais agudas. Rev Prática Hospitalar. 2005;7(40):42-7.

3. Lopes AC, Souza LJ, Paravidine PCL, Lima, GAC, Gomes MAE, Araújo PD. Encefalite herpética em paciente do sexo feminino de 48 anos previamente hígida. Rev Soc Bras Clin Med. 2008;6(2):79-82.

4. Fica AC, Pérez CC, Reyes PO, Gallardo SP, Calvo XP, Salinas AMS. Encefalitis herpética. Serie clínica de 15 casos confirmados por reacción de polimerasa en cadena. Rev Chil Infect. 2005;22(1):38-46.

5. McGrath N, Anderson NE, Croxson MC, Powell KF. Herpes simplex encephalitis treated with acyclovir: diagnosis and long term outcome. J Neurol Neurosurg Psychiatry. 1997;63(3):321-6.

6. Domingues RB, Panutti CS, Fink MCD, Tsanaclis AMC. Diagnósticos alternativos em pacientes com suspeita de encefalite por Herpes simplex e negativos à reação de cadeia polimerase (PCR). Arq Neuropsiquiatr. 2000;58(4):1073-80.

7. Więdłocha M, Marcinowicz P, Stańczykiewicz B. Psychiatric aspects of herpes simplex encephalitis, tick-borne encephalitis and herpes zoster encephalitis among immunocompetent patients. Adv Clin Exp Med. 2015;24(2):361-71.

8. Kuroda H. [Update on Herpes Simplex Encephalitis]. Brain Nerve. 2015;67(7):931-9.

9. Lopes ACGA, Nunes SICV. Epilepsia, psicose e religiosidade - Caso clínico. J Bras Psiquiatr. 2015;64(2):169-72 